\title{
Characteristic Symptoms in Women with Ischemic Heart Disease
}

\author{
Angela H. E. M. Maas ${ }^{1}$
}

Published online: 2 May 2019

(C) The Author(s) 2019

\begin{abstract}
Purpose of Review Advances in coronary imaging techniques have revealed that there are important sex differences in the pattern of ischemic heart disease. In this review, we aim to summarize our current knowledge and focus on the relation between a distinct symptom presentation in women and their underlying type of coronary artery disease.

Recent Findings Women in the age group 40-70 years more often have non-obstructive coronary artery disease (CAD) and coronary vasomotor disorders compared with the traditional obstructive CAD as seen in men. These differences in pathophysiology translate into another symptom presentation which we should rather call characteristic than atypical. Women at risk for coronary vasomotor disorders often have co-morbidities and an enhanced pro-inflammatory state, which leads the way to the appropriate diagnosis. Progress has been made with invasive testing to better discriminate between coronary spasm and microvascular dysfunction. Treatment options are still limited and often disappointing for this heterogeneous patient population. Summary Sex differences in ischemic heart disease truly exist and have been clearly defined over the past years. We should therefore approach female patients according to this acquired knowledge. The challenge for the coming years will be a more tailored diagnostic and therapeutic approach for symptomatic women at middle-age.
\end{abstract}

Keywords Atherosclerosis $\cdot$ Coronary spasm $\cdot$ Ischemic heart disease $\cdot$ Microvascular dysfunction $\cdot$ Women

\section{Introduction}

Female patients have historically been confusing for cardiologists. Being educated in treating obstructive coronary artery disease (CAD), its different pattern of symptoms and atherosclerosis have surprised so many. In the early 1990s of the last century, it was first assumed that women were discriminated in diagnostics and treatment of CAD $[1,2]$. In addition, it was considered that gender issues in CAD were mainly driven by a different way in symptom expression and not by biological (sex) differences.

With the evolving knowledge gained by many percutaneous coronary intervention (PCI) research programs for acute coronary syndrome (ACS) and elective PCI over the past decades, we have learned that sex differences in

This article is part of the Topical Collection on Women and Heart Disease

Angela H. E. M. Maas

angela.maas@radboudumc.nl

1 Department of Cardiology, Radboud University Medical Center, Geert-Grooteplein Zuid 10, route 616, 6525

GA Nijmegen, The Netherlands ischemic heart disease (IHD) truly exist. Obstructive CAD occurs 7-10 years later in women than in men, and women have fewer focal stenotic lesions at all ages [3]. They have a lower plaque burden with less vascular calcifications, a more diffuse pattern of atherosclerosis, and more often soft plaques and erosive lesions [4-7]. Only a quarter of all included patients in PCI registries are women, reflecting their different pattern of disease [8••]. When having an ACS or an elective PCI, women are older with a higher clustering of traditional CVD risk factors. Coronary vasomotor disorders, such as coronary artery spasm (CAS) and endothelial dysfunction, represent a major cause of ischemic cardiac symptoms in middle-aged women.

Differences in underlying pathophysiology lead to a more distinct presentation of angina symptoms and warrant a more gender-sensitive, diagnostic, and therapeutic approach than the usual male-oriented pathway. As appropriate diagnoses are often lacking, this leads to an ongoing under-treatment and results in adverse outcomes in the long run. It is therefore not amazing that we observe a rise in the number of hospitalizations for ACS in younger women, even under 55 years of age $\left[9 \bullet, 10^{\bullet}\right]$. 


\section{Ischemia with Non-obstructive Coronary Arteries}

Women with symptoms of angina have twice as often ischemia with non-obstructive coronary arteries (INOCA) compared with men $[3,11]$. Another often used term is NOCAD, meaning non-obstructive coronary artery disease. The overemphasis of obstructive CAD over INOCA in our guidelines is one of the main reasons that women are still less well treated than men [12]. When coronary stenosis is less than $50 \%$ at angiography, with a fractional flow reserve (FFR) $\geq 0.80$, it is considered to be not significant. Non-obstructive CAD is often present in combination with coronary vasomotor disorders, such as spasm and endothelial dysfunction of the larger and smaller branches of the coronary tree $[13,14 \cdot]$. In most symptomatic patients, intravascular ultrasound (IVUS) shows some signs of coronary atherosclerosis [15]. However, IVUS is not routinely carried out in patients with INOCA, which may lead to the misdiagnosis of "clean arteries" and subsequent undertreatment of symptoms and risk factors. It has been demonstrated that INOCA is not a benign condition and that it has a higher 5 -year event rate in symptomatic women compared with men, especially when signs of ischemia are present $[16,17]$. Women with INOCA represent a very heterogeneous group, regarding the extent of atherosclerosis, the presence of risk factors, symptoms, and functional impairment.

\section{Fluctuating Symptoms in Women with INOCA}

The clinical evaluation of symptoms of angina pectoris in women is still considered along with the male standard of obstructive CAD. The combination of INOCA with vasomotor disorders frequently occurs in young and middle-aged women. Whereas typical symptoms of angina are more related to epicardial stenoses, the combination of INOCA with vasomotor dysfunction has other characteristics. Depending on the involvement of coronary spasm and endothelial dysfunction, chest pain may occur both at rest and during exercise and often varies over time. Symptoms fluctuate within days and weeks and may present in a crescendo/decrescendo pattern. The majority of patients feel unusually tired with a lack of energy. The traditional risk factors such as hypertension and dyslipidemia may serve as triggers for vascular dysfunction and coronary spasm. Stress-related factors are equally important risk factors and can also act as triggers for vascular dysfunction [18, 19•, 20]. Stressful circumstances and events often aggravate the duration and intensity of symptoms [21].

Lack of patient awareness and gender differences in communication styles frequently hamper the early recognition of angina in women. In addition, women's communication is more likely to be emotional, subjective, polite, and selfrevealing with more concern and awareness for the feelings of others. Men usually report their symptoms in a direct way, while female patients ask more questions, present more and diverse symptoms, and give more detailed histories of their activities. This can be misleading to both female patients and their doctors for the correct interpretation of their cardiac symptoms. The diverse symptoms of stable angina in women are depicted in Table 1.

\section{Coronary Microvascular Dysfunction Type 1 Dominates in Women}

In more than $60 \%$ of patients with INOCA, there is concomitant involvement of coronary microvascular dysfunction (CMD) $[22,23]$. Functional and/or structural abnormalities in the coronary microcirculation result in impaired vasodilatation (endothelium-dependent and endothelium-independent mechanisms) and an increased vasoconstriction level caused by various stimuli $[24,25 \bullet \cdot]$. Type $1 \mathrm{CMD}$ with functional impairment typically occurs in women between 40 and 70 years of age and is characterized by the absence of obstructive $\mathrm{CAD}$ or other structural heart diseases. Important contributing factors are obesity, smoking, and traditional cardiovascular risk factors (dyslipidemia, hypertension, diabetes). In addition, an enhanced inflammatory state such as in rheumatic diseases and chronic intestinal bowel syndromes also predispose for CMD [26••, 27]. It is increasingly acknowledged that small vessel damage in the heart is a systemic phenomenon and that these patients have generalized endothelial dysfunction leading to abnormal vascular reactivity $[25 \bullet \bullet, 28 \bullet \cdot]$. An enhanced inflammatory state with signs of premature vascular dysfunction may also be the reason that patients with type 1 CMD relatively frequently report a previous history of migraine and severe hypertensive pregnancy disorders [29, $30 \bullet$. We have recently shown that women after preeclamptic pregnancies have a twofold higher risk for identifiable coronary calcium with $\mathrm{CT}$ (CAC score) compared with women after normotensive pregnancies [31•]. It is therefore essential to ask for these life events and co-morbidities when considering the diagnosis type $1 \mathrm{CMD}$ (Fig. 1) [32].

Symptoms in patients with type 1 CMD overlap strongly with INOCA and share their fluctuating and often unpredictable character. Angina pectoris can occur both during exercise and spontaneous in the evening or at night. Affected patients often report to be extremely tired in the days after many activities.

\section{Diagnosis and Management of Coronary Vasomotor Disorders}

The Coronary Vasomotion Disorders International Study Group (COVADIS) has recently published two separate consensus statements on vasospastic angina and microvascular 
Table 1 Classification of angina with female-specific aspects ()

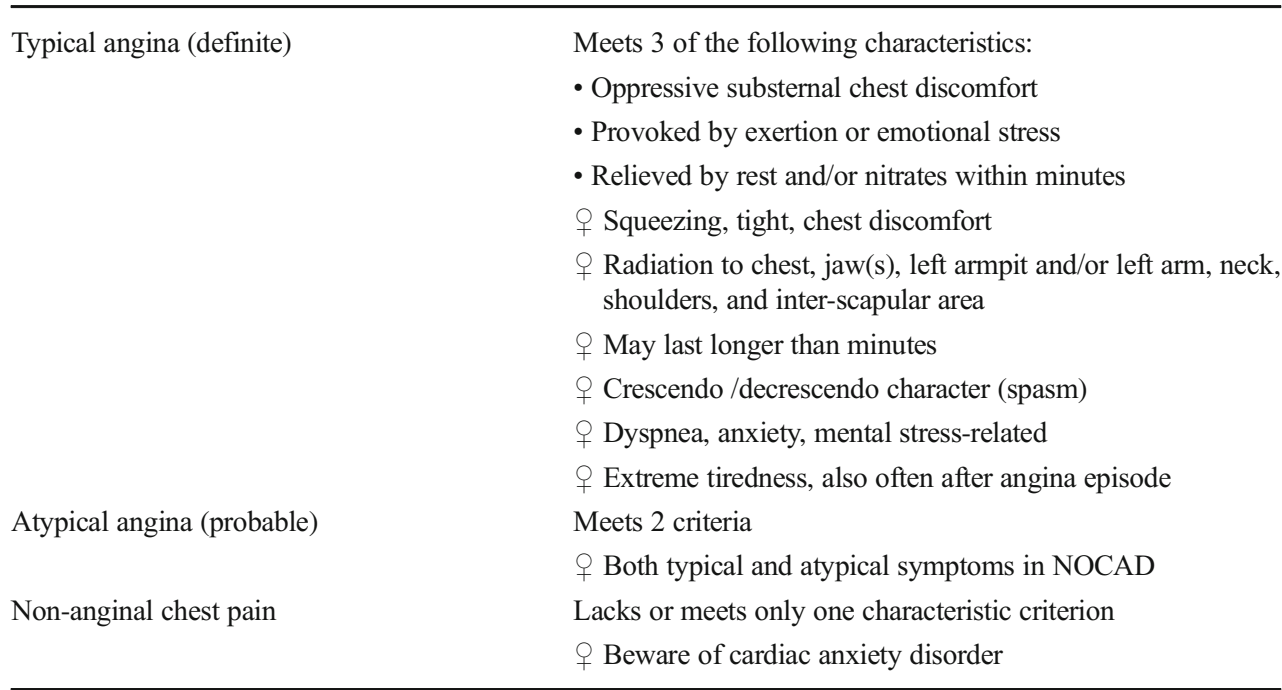

Adapted from: Montalescot G et al., 2013 ESC guidelines stable CAD angina as guidance for coronary vasomotor disorders [33, 34••]. As the diagnosis cannot be established based on symptoms alone, additional non-invasive and invasive testing for ischemia are recommended. With positron emission tomography (PET) using ammonia, coronary flow reserve (CFR) can be measured. A CFR $<2.5$ is considered to be abnormal and a CFR $<2.0$ is associated with adverse cardiac outcomes [35]. Despite, in many symptomatic patients, PET scans are not abnormal, presumably because vasospastic angina dominates over CMD.

Obstructive $\mathrm{CAD}$ can be ruled out with $\mathrm{CT}$ angiography when a coronary angiography has not been done previously. The best way to establish the diagnosis of vasomotor disorders is to perform invasive measures of the index of microvascular resistance
(IMR) and CFR and to perform vasoreactivity testing with acetylcholine. This can be safely done by expert invasive cardiologists, using a standardized protocol [36, 37]. These invasive tests are important to discriminate between vasospasm of the epicardial coronary arteries and the coronary microvasculature. Abnormal test results are associated with adverse outcomes [38].

Treatment of coronary vasomotor disorders starts with lifestyle interventions and appropriate and adequate control of the traditional risk factors. The use of anti-platelet therapy is not routinely recommended, whereas statins are primarily indicated when lipid levels are elevated. Importantly, blood pressure should be more strictly treated than what the guidelines advice. In most patients, short-acting nitrates are helpful to
Fig. 1 Life course approach in women with angina pectoris at middle-age

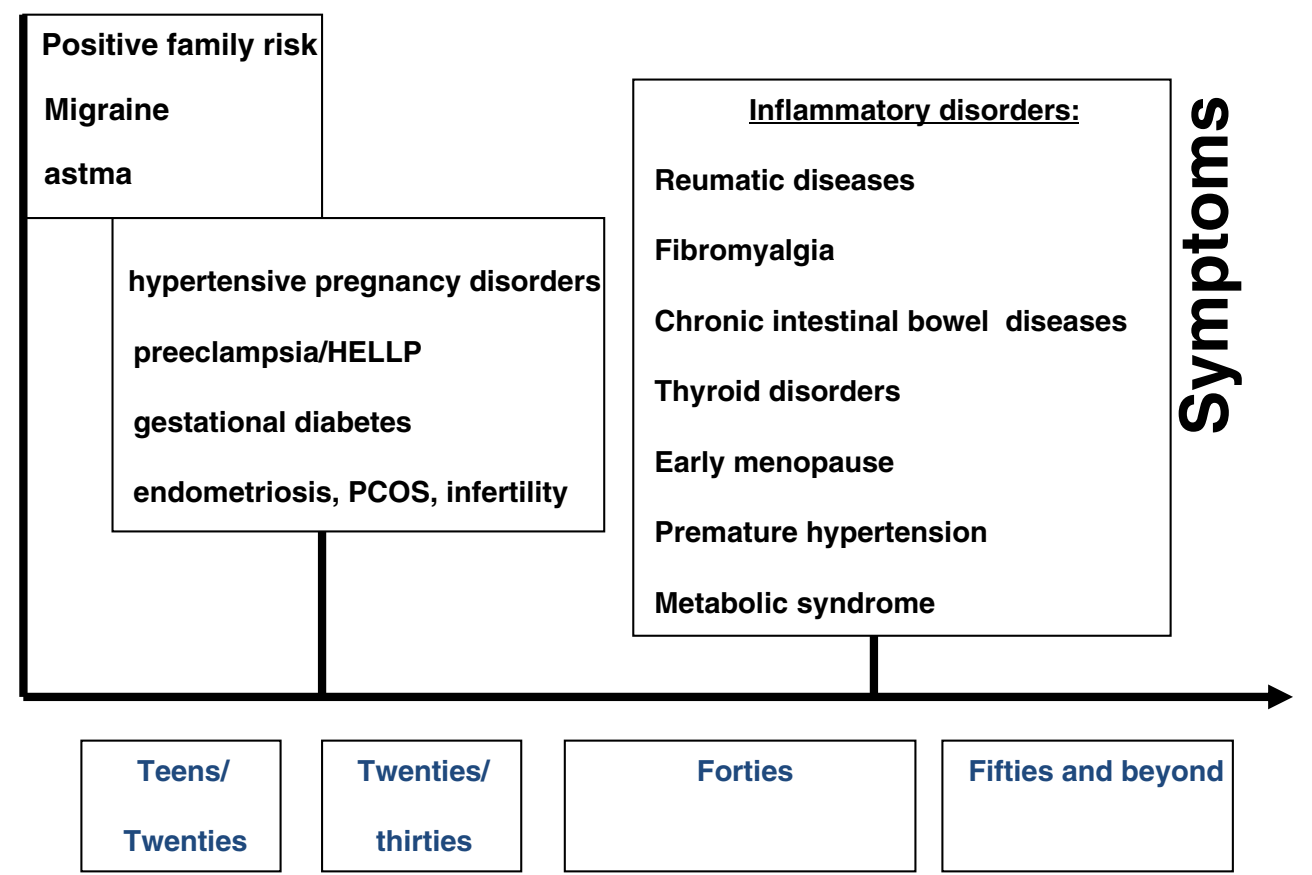


relieve symptoms, but not at all times [12, 39]. Long-acting nitrates may even aggravate symptoms. Depending on the resting heart rate, high doses of calcium-antagonists can be given, preferably diltiazem, even combined with low doses selective beta-blockers. In patients with refractory angina, non-traditional treatment options can be beneficial. These include xanthine derivates, ivabradine, nicorandil, and ranolazine $[12,39,40]$. The use of postmenopausal hormone replacement therapy has no additional beneficial effect in women with CMD. As there is no standard treatment suited for every patient, it may take time to find the best individual options. Stress reduction programs with mindfulness and yoga can be helpful in symptom reduction.

\section{Conclusion}

Advances in coronary imaging and the increased attention to coronary vasomotor disorders over the past years are important reasons why female patients are now more into the spotlight. Progress has been made in better defining their characteristic symptoms with important diagnostic and therapeutic steps forward. However, many questions are still unresolved. More fine-tuning in diagnosis and therapy is needed to better serve each individual patient.

\section{Compliance with Ethical Standards}

Conflict of Interest The author declares that she has no conflict of interest.

Human and Animal Rights and Informed Consent This article does not contain any studies with human or animal subjects performed by any of the authors.

Open Access This article is distributed under the terms of the Creative Commons Attribution 4.0 International License (http:// creativecommons.org/licenses/by/4.0/), which permits unrestricted use, distribution, and reproduction in any medium, provided you give appropriate credit to the original author(s) and the source, provide a link to the Creative Commons license, and indicate if changes were made.

\section{References}

Papers of particular interest, published recently, have been highlighted as:

- Of importance

• Of major importance

1. Steingart, R.M., Packer M., Hamm P., Coglianese M.E., Gersh B., Geltman E.M., Sollano J., Katz S., Moyé L., Basta L.L., Lewis S.J., Gottlieb S.S., Bernstein V., McEwan P., Jacobson K., Brown E.J., Kukin M.L., Kantrowitz N.E., Pfeffer M.A., Sex differences in the management of coronary artery disease. Survival and Ventricular Enlargement Investigators. N Engl J Med, 1991. 325(4): p. 226-230.

2. Ayanian JZ, Epstein AM. Differences in the use of procedures between women and men hospitalized for coronary heart disease. $\mathrm{N}$ Engl J Med. 1991;325(4):221-5.

3. Johnston N, Schenck-Gustafsson K, Lagerqvist B. Are we using cardiovascular medications and coronary angiography appropriately in men and women with chest pain? Eur Heart J. 2011;32(11): 1331-6.

4. Qureshi W, Blaha MJ, Nasir K, al-Mallah MH. Gender differences in coronary plaque composition and burden detected in symptomatic patients referred for coronary computed tomographic angiography. Int J Card Imaging. 2013;29(2):463-9.

5. Smilowitz NR, Sampson BA, Abrecht CR, Siegfried JS, Hochman JS, Reynolds HR. Women have less severe and extensive coronary atherosclerosis in fatal cases of ischemic heart disease: an autopsy study. Am Heart J. 2011;161(4):681-8.

6. Frink RJ. Gender gap, inflammation and acute coronary disease: are women resistant to atheroma growth? Observations at autopsy. J Invasive Cardiol. 2009;21(6):270-7.

7. Han SH, Bae JH, Holmes DR, Lennon RJ, Eeckhout E, Barsness $\mathrm{GW}$, et al. Sex differences in atheroma burden and endothelial function in patients with early coronary atherosclerosis. Eur Heart J. 2008;29(11):1359-69.

8.• Chieffo A, et al. Percutaneous coronary and structural interventions in women: a position statement from the EAPCI Women Committee. EuroIntervention. 2018;14(11):e1227-35 This paper from the EAPCI Women Committee highlights the ongoing issues with the diagnosis and treatment of CAD in women. Differences in the pathophysiology between sexes are summarized, highlighting the need for greater awareness amongst healthcare professionals to enable the best evidence-based therapies for women and men.

9. Gabet A, et al. Acute coronary syndrome in women: rising hospitalizations in middle-aged French women, 2004-14. Eur Heart J. 2017;38(14):1060-5 This nationwide study showed substantial rising trends in STEMI annual incidence, especially among younger women. This increase could be attributed to increase in smoking and obesity. There is growing evidence of higher short-term mortality of CHD in women.

10. Arora S, et al. Twenty year trends and sex differences in young adults hospitalized with acute myocardial infarction. Circulation. 2019;139(8):1047-56 The proportion of AMI hospitalizations attributable to young patients increased from 1995 to 2014 and was especially pronounced among women. Compared with young men, young women presenting with AMI had a lower likelihood of receiving guideline-based AMI therapies.

11. Jespersen L, Hvelplund A, Abildstrom SZ, Pedersen F, Galatius S, Madsen JK, et al. Stable angina pectoris with no obstructive coronary artery disease is associated with increased risks of major adverse cardiovascular events. Eur Heart J. 2012;33(6):734-44.

12. Task Force M, et al. 2013 ESC guidelines on the management of stable coronary artery disease: the Task Force on the management of stable coronary artery disease of the European Society of Cardiology. Eur Heart J. 2013;34(38):2949-3003.

13. Marzilli M, Merz CNB, Boden WE, Bonow RO, Capozza PG, Chilian WM, et al. Obstructive coronary atherosclerosis and ischemic heart disease: an elusive link! J Am Coll Cardiol. 2012;60(11): 951-6.

14. Bairey Merz CN, Pepine CJ, Walsh MN, Fleg JL, Camici PG, Chilian WM, et al. Ischemia and no obstructive coronary artery disease (INOCA): developing evidence-based therapies and research agenda for the next decade. Circulation. 2017;135(11): 1075-92 This document provides a summary of findings and recommendations for the development of an integrated approach for identifying and managing patients with ischemia 
with no obstructive coronary arteries and outlines knowledge gaps in the area.

15. Lee BK, Lim HS, Fearon WF, Yong AS, Yamada R, Tanaka S, et al. Invasive evaluation of patients with angina in the absence of obstructive coronary artery disease. Circulation. 2015;131(12):105460 .

16. Sedlak TL, Lee M, Izadnegahdar M, Merz CNB, Gao M, Humphries KH. Sex differences in clinical outcomes in patients with stable angina and no obstructive coronary artery disease. Am Heart J. 2013;166(1):38-44.

17. Gulati M, Cooper-DeHoff RM, McClure C, Johnson BD, Shaw LJ, Handberg EM, et al. Adverse cardiovascular outcomes in women with nonobstructive coronary artery disease: a report from the Women's Ischemia Syndrome Evaluation Study and the St James Women Take Heart Project. Arch Intern Med. 2009;169(9):843-50.

18. Konst RE, et al. Different cardiovascular risk factors and psychosocial burden in symptomatic women with and without obstructive coronary artery disease. Eur J Prev Cardiol. 2018: 2047487318814298

19. Kivimaki, M. and A. Steptoe, Effects of stress on the development and progression of cardiovascular disease. Nat Rev Cardiol, 2018. 15(4): p. 215-229. Expert review on the role of stress in cardiovascular disease. Stress has an important role as a disease trigger in individuals who already have a high atherosclerotic plaque burden, and as a determinant of prognosis and outcome in those with preexisting cardiovascular or cerebrovascular disease.

20. Anand SS, Islam S, Rosengren A, Franzosi MG, Steyn K, Yusufali $\mathrm{AH}$, et al. Risk factors for myocardial infarction in women and men: insights from the INTERHEART study. Eur Heart J. 2008;29(7): 932-40.

21. Low CA, Thurston RC, Matthews KA. Psychosocial factors in the development of heart disease in women: current research and future directions. Psychosom Med. 2010;72(9):842-54.

22. Reis SE, Holubkov R, Smith AJC, Kelsey SF, Sharaf BL, Reichek $\mathrm{N}$, et al. Coronary microvascular dysfunction is highly prevalent in women with chest pain in the absence of coronary artery disease: results from the NHLBI WISE study. Am Heart J. 2001;141(5): 735-41.

23. Sara JD, Widmer RJ, Matsuzawa Y, Lennon RJ, Lerman LO, Lerman A. Prevalence of coronary microvascular dysfunction among patients with chest pain and nonobstructive coronary artery disease. JACC Cardiovasc Interv. 2015;8(11):1445-53.

24. Camici PG, d'Amati G, Rimoldi O. Coronary microvascular dysfunction: mechanisms and functional assessment. Nat Rev Cardiol. 2015;12(1):48-62.

25.• Kaski JC, Crea F, Gersh BJ, Camici PG. Reappraisal of ischemic heart disease. Circulation. 2018;138(14):1463-80 Expert document on the importance of microvascular dysfunction in patients with ischemic heart disease. Structural and functional disturbances of the coronary microcirculation importantly contribute to obstructive and non-obstructive CAD.

26.• Faccini A, Kaski JC, Camici PG. Coronary microvascular dysfunction in chronic inflammatory rheumatoid diseases. Eur Heart J. 2016;37(23):1799-806 Inflammation can affect coronary microvascular function and contributes to the development of myocardial ischemia and cardiovascular events, even in the absence of obstructive epicardial coronary artery disease. The possible link between systemic inflammation and CMD may lead to an improvement in the treatment of $\mathrm{CV}$ involvement in chronic inflammatory disorders. Expert paper.

27. Gianturco L, Bodini BD, Atzeni F, Colombo C, Stella D, SarziPuttini P, et al. Cardiovascular and autoimmune diseases in females: the role of microvasculature and dysfunctional endothelium. Atherosclerosis. 2015;241(1):259-63.

28.• Ford TJ, et al. Systemic microvascular dysfunction in microvascular and vasospastic angina. Eur Heart J. 2018;39(46):4086-97
Case-control study to investigate peripheral small artery changes in two distinct groups of INOCA - those with microvascular angina (MVA) and those with vasospastic angina (VSA). It was found that systemic microvascular abnormalities are common in patients with MVA and VSA. These mechanisms may involve ET-1 and were characterized by endothelial dysfunction and enhanced vasoconstriction.

29. Napoli R, Guardasole V, Zarra E, Matarazzo M, D'Anna C, Sacca F, et al. Vascular smooth muscle cell dysfunction in patients with migraine. Neurology. 2009;72(24):2111-4.

30. Cornelius DC. Preeclampsia: from inflammation to immunoregulation. Clin med insights blood Disord. 2018;11:1179545X17752325 Expert paper on enhanced inflammation in women after preeclampsia (PE). PE is associated with chronic immune activation characterized by persistently higher levels of proinflammatory cytokines and diminished immunoregulatory factors. This immune imbalance promotes an inflammatory state during PE.

31. Zoet GA, Benschop L, Boersma E, Budde RPJ, Fauser BCJM, van der Graaf Y, et al. Prevalence of subclinical coronary artery disease assessed by coronary computed tomography angiography in 45 - to 55-year-old women with a history of preeclampsia. Circulation. 2018;137(8):877-9 First paper to decribe a twofold higher risk of any CAC as sign of subclinical atherosclerosis in young women after preeclampsia.

32. Elias-Smale SE, Gunal A, Maas AH. Gynecardiology: distinct patterns of ischemic heart disease in middle-aged women. Maturitas. 2015;81(3):348-52.

33. Beltrame JF, Crea F, Kaski JC, Ogawa H, Ong P, Sechtem U, et al. The who, what, why, when, how and where of vasospastic angina. Circ J. 2016;80(2):289-98.

34.• Ong P, et al. International standardization of diagnostic criteria for microvascular angina. Int J Cardiol. 2018;250:16-20 Expert document on the criteria to establish the diagnosis of CMD.

35. Murthy VL, Naya M, Taqueti VR, Foster CR, Gaber M, Hainer J, et al. Effects of sex on coronary microvascular dysfunction and cardiac outcomes. Circulation. 2014;129(24):2518-27.

36. Wei J, Mehta PK, Johnson BD, Samuels B, Kar S, Anderson RD, et al. Safety of coronary reactivity testing in women with no obstructive coronary artery disease: results from the NHLBIsponsored WISE (Women's Ischemia Syndrome Evaluation) study. JACC Cardiovasc Interv. 2012;5(6):646-53.

37. Ong P, Athanasiadis A, Borgulya G, Vokshi I, Bastiaenen R, Kubik $\mathrm{S}$, et al. Clinical usefulness, angiographic characteristics, and safety evaluation of intracoronary acetylcholine provocation testing among 921 consecutive white patients with unobstructed coronary arteries. Circulation. 2014;129(17):1723-30.

38. AlBadri A, Bairey Merz CN, Johnson BD, Wei J, Mehta PK, CookWiens $\mathrm{G}$, et al. Impact of abnormal coronary reactivity on long-term clinical outcomes in women. J Am Coll Cardiol. 2019;73(6):684 93.

39. Ong P, Athanasiadis A, Sechtem U. Pharmacotherapy for coronary microvascular dysfunction. Eur Heart J Cardiovasc Pharmacother. 2015;1(1):65-71.

40. Rambarat CA, Elgendy IY, Handberg EM, Bairey Merz CN, Wei J, Minissian MB, et al. Late sodium channel blockade improves angina and myocardial perfusion in patients with severe coronary microvascular dysfunction: Women's Ischemia Syndrome Evaluation-Coronary Vascular Dysfunction ancillary study. Int $\mathbf{J}$ Cardiol. 2019;276:8-13.

Publisher's Note Springer Nature remains neutral with regard to jurisdictional claims in published maps and institutional affiliations. 